\title{
Microbial community structures differentiated in a single-chamber air-cathode microbial fuel cell fueled with rice straw hydrolysate
}

\author{
Zejie Wang ${ }^{1,4}$, Taekwon Lee ${ }^{3,5}$, Bongsu Lim', Chansoo Choi ${ }^{2^{*}}$ and Joonhong Park ${ }^{3}$
}

\begin{abstract}
Background: The microbial fuel cell represents a novel technology to simultaneously generate electric power and treat wastewater. Both pure organic matter and real wastewater can be used as fuel to generate electric power and the substrate type can influence the microbial community structure. In the present study, rice straw, an important feedstock source in the world, was used as fuel after pretreatment with diluted acid method for a microbial fuel cell to obtain electric power. Moreover, the microbial community structures of anodic and cathodic biofilm and planktonic culturewere analyzed and compared to reveal the effect of niche on microbial community structure.

Results: The microbial fuel cell produced a maximum power density of $137.6 \pm 15.5 \mathrm{~mW} / \mathrm{m}^{2}$ at a COD concentration of $400 \mathrm{mg} / \mathrm{L}$, which was further increased to $293.33 \pm 7.89 \mathrm{~mW} / \mathrm{m}^{2}$ through adjusting the electrolyte conductivity from $5.6 \mathrm{mS} / \mathrm{cm}$ to $17 \mathrm{mS} / \mathrm{cm}$. Microbial community analysis showed reduction of the microbial diversities of the anodic biofilm and planktonic culture, whereas diversity of the cathodic biofilm was increased. Planktonic microbial communities were clustered closer to the anodic microbial communities compared to the cathodic biofilm. The differentiation in microbial community structure of the samples was caused by minor portion of the genus. The three samples shared the same predominant phylum of Proteobacteria. The abundance of exoelectrogenic genus was increased with Desulfobulbus as the shared most abundant genus; while the most abundant exoelectrogenic genus of Clostridium in the inoculum was reduced. Sulfate reducing bacteria accounted for large relative abundance in all the samples, whereas the relative abundance varied in different samples.

Conclusion: The results demonstrated that rice straw hydrolysate can be used as fuel for microbial fuel cells; microbial community structure differentiated depending on niches after microbial fuel cell operation; exoelectrogens were enriched; sulfate from rice straw hydrolysate might be responsible for the large relative abundance of sulfate reducing bacteria.
\end{abstract}

Keywords: Microbial fuel cell, Microbial diversity, 454-pyrosequencing, Rice straw biomass

\section{Background}

Microbial fuel cells (MFCs) are devices to produce electric energy from organic matters and treat wastewaters in both anode and cathode chambers [1,2]. Pure organic compound, real wastewater, and biomass have been successfully used as fuel for power generation in MFCs [3]. Rice straw is one of the most abundant biomasses, mainly composed of cellulose, hemicellulose, and some lignin [4]. The hemicellulose can be easily degraded to

\footnotetext{
* Correspondence: cse110@dju.kr

2Department of Applied Chemistry, Daejeon University, Daejeon, South Korea Full list of author information is available at the end of the article
}

its constituent sugars through acidic and/or enzymatic hydrolysis; the produced sugars can be further used as substrate to produce organic acids or bioethanol $[5,6]$. Therefore, the sugars produced from the rice straw hydrolysate might be used as a useful fuel for power generation from MFCs.

In MFCs, microbes play crucial roles in energy output and organic contaminants removal [7]. The ability of microbes to transfer electrons in the anode can significantly affect the performance of MFCs. Anodic microbial communities were reported to be significantly related with the types of substrates fed into the anode chamber [8]. For example, Acetobacterium species (sp.), Geobacter sp., and

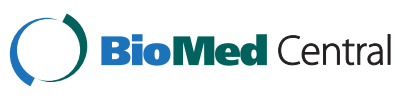


Arcobacter sp. were detected in the anodic biofilm fed with formate [9]; however, Enterobacter sp. was the dominant bacterial species in the MFC with glucose as substrate [10]. For air-cathode MFCs, biofilm was commonly formed on the water-facing side of the cathode. It was discovered that the formation of biofilm on the Pt-loaded air-cathode could decrease the power output due to the increased cathodic resistance and limited proton transfer rate [11]; however, recent research demonstrated that the biofilm formation on a bare air-cathode could enhance the electric power output from air-cathode MFCs [12]. The different research conclusions might be caused by different air-cathode configurations. Moreover, the cathodic biofilm in a Pt-loaded air-cathode was observed to be capable of removing nitrogen, with enhanced removal efficiency due to the pre-accumulation of nitrifying biofilm [13]. The aforementioned results indicate that the cathodic biofilm deserves further research.

Therefore, the purpose of the present study was to evaluate the availability of diluted acid-treated rice straw hydrolystate as fuel for an air-cathode MFC. In addition, microbial analysis at high resolution level using 454 pyrosequencing was carried out to evaluate the effect of the rice straw hydrolystate and niches on the microbial diversity and community.

\section{Results and discussion \\ Performance of the MFC}

After addition of the rice straw hydrolysate as an anodic solution, cell voltage was immediately increased with no lag time. Stable voltage increased from $177.6 \pm 17.3 \mathrm{mV}$ for chemical oxygen demand (COD) of $100 \mathrm{mg} / \mathrm{L}$ to $524.7 \pm$ $3.2 \mathrm{mV}$ for COD of $400 \mathrm{mg} / \mathrm{L}$, in response to the decrease in anodic potential from $-110.5 \pm 21.6 \mathrm{mV}$ to $-508.7 \pm$ $6.9 \mathrm{mV}$ (Figure 1a and b). The results indicated that organic matters produced from the hydrolysate could be easily utilized by anodic microorganism and release electrons, decreasing the anodic potential and consequently increasing the cell voltage [14]. The stable anodic potential was appropriately $-300 \mathrm{mV}$ (versus standard hydrogen electrode), similar to that of $-340 \mathrm{mV}$ observed by Wang et al. [15]. For relatively low COD concentrations (100 and $150 \mathrm{mg} / \mathrm{L}$ ), the cell voltage showed a large difference between two separate cycles; while the COD concentration increased to $200 \mathrm{mg} / \mathrm{L}$, the voltage was well reproduced, suggesting that the saturated COD for voltage output was $200 \mathrm{mg} / \mathrm{L}$. The saturated COD concentration in the present study was far lower than that of the $1,000 \mathrm{mg} / \mathrm{L}$ observed when wheat straw hydrolysate was used as fuel in a dual-chamber MFC [16]. A lower saturated COD concentration indicated higher capacity of power production from the fuel based on the same quantity. Furthermore, the discharge time increased from $17.1 \pm 1.2$ hours to $49.8 \pm$ 2.4 hours relying on the increased COD concentration.
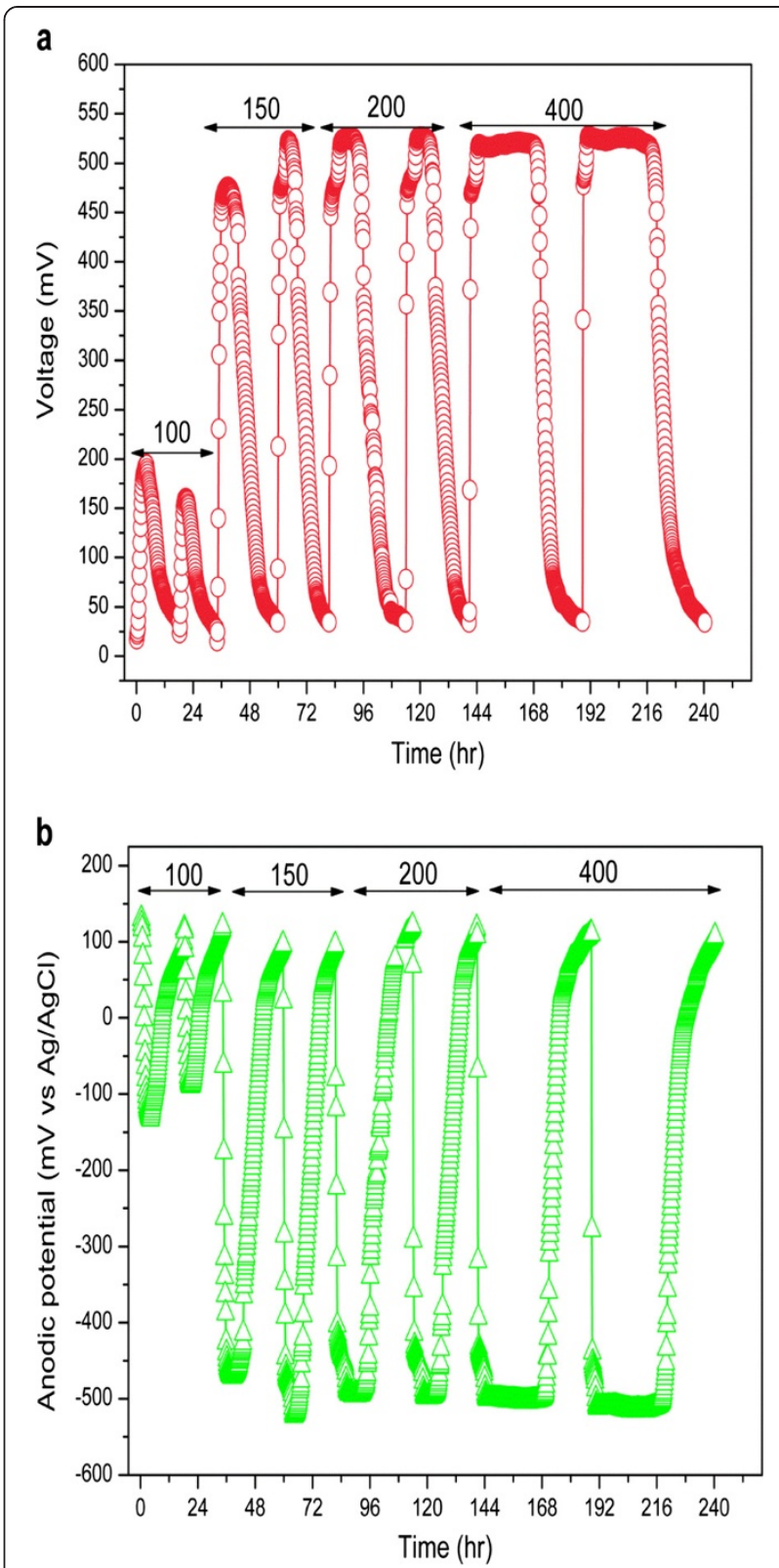

Figure 1 Voltage response of the microbial fuel cell (MFC) to chemical oxygen demand (COD) under batch-mode operation. (a) Voltage output and (b) anodic potential as a function of COD concentration at a fixed external resistance of $500 \Omega$. Figures on the plot represent the COD concentrations ( $\mathrm{mg} / \mathrm{L})$.

Coulombic efficiency (CE) indicates the ratio of total electrons recovered as electric current from organic matter. In this study, the CE was calculated in the range from $8.5 \%$ to $17.9 \%$, and the COD removal efficiency ranged from $49.4 \pm 4.0 \%$ to $72.0 \pm 1.7 \%$ (Figure 2 ). The present CE was lower than that of wheat straw- [16] or corn stover biomass-fuelled [17] MFCs, which were $15.5 \%$ to $37.1 \%$ and $19.3 \%$ to $25.6 \%$, respectively; whereas it was higher than that previously reported using real wastewater 


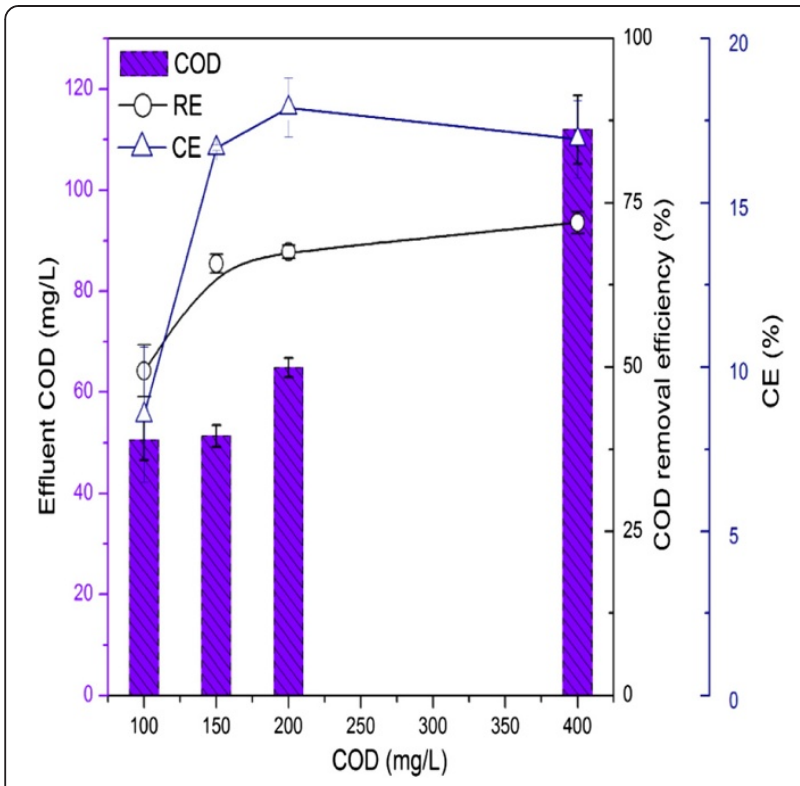

Figure 2 Effluent chemical oxygen demand (COD) concentration and COD removal efficiency (RE) and coulombic efficiency (CE). The initial COD concentration was 100, 150, 200, and $400 \mathrm{mg} / \mathrm{L}$ with an external resistance of $500 \Omega$.

as fuels, which for example, is less than $1 \%$ for fermented wastewater [18], and a maximum $\mathrm{CE}$ of $8 \%$ for starch processing wastewater [19]. For air-cathode MFCs, oxygen diffused to the anode chamber can aerobically consume substrates other than anaerobically generated electrons, which would be the reason for the low $\mathrm{CE}$ of air-cathode MFCs [20].

The maximum power density $\left(\mathrm{P}_{\max }\right)$ was determined as $137.6 \pm 15.5 \mathrm{~mW} / \mathrm{m}^{2}$ for COD of $400 \mathrm{mg} / \mathrm{L}$, at a current density of $0.28 \mathrm{~A} / \mathrm{m}^{2}$ (Figure 3a). It was further promoted to $293.3 \pm 7.9 \mathrm{~mW} / \mathrm{m}^{2}$ at a current density of $0.90 \mathrm{~A} / \mathrm{m}^{2}$ when the solution conductivity was adjusted from $5.6 \mathrm{mS} /$ $\mathrm{cm}$ to $17 \mathrm{mS} / \mathrm{cm}$ through addition of $\mathrm{NaCl}$. Consequently, the internal resistance $\left(R_{\text {int }}\right)$ of the MFC was decreased from $714.4 \pm 19.1 \Omega$ to $229.9 \pm 14.5 \Omega$. Moreover, conductivity adjustment enhanced the anodic performance, relieving the mass transfer limitation while limiting the cathode performance (Figure $3 \mathrm{~b}$ ).

The $\mathrm{P}_{\max }\left(293.33 \pm 7.89 \mathrm{~mW} / \mathrm{m}^{2}\right)$ was larger than that of wheat straw hydrolysate $\left(123 \mathrm{~mW} / \mathrm{m}^{2}\right)$. Based on the maximum power of $1.08 \mathrm{~mW}\left(293.33 \mathrm{~mW} / \mathrm{m}^{2}\right)$ and the stable discharge time of 24 hours, $2.592 \times 10^{-5} \mathrm{kWh}$ of electric power can be extracted from a COD concentration of $400 \mathrm{mg} / \mathrm{L}$. The worldwide generation rate of rice straw was about 731 million dry tons in 2007. Therefore, a total amount of $1.51 \times 10^{18} \mathrm{mg} / \mathrm{L}$ COD can be produced, from which $9.78 \times 10^{10} \mathrm{kWh}$ of electric power can be extracted. In 2007, the worldwide per capita consumption of electric power was 2,752 kWh (http://www.chinaero.com.cn). Therefore, the electric power extracted from rice straw

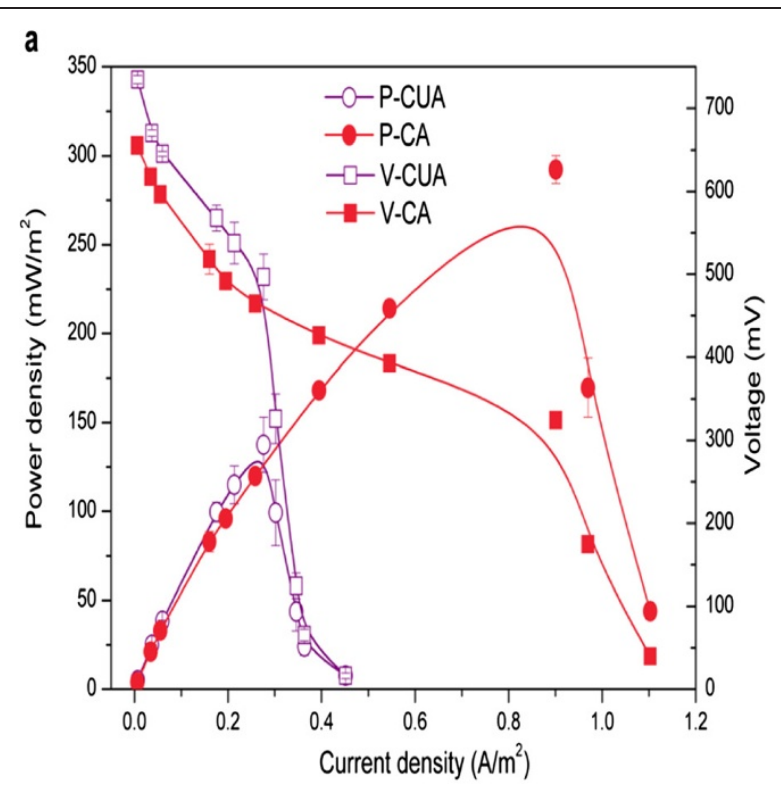

b

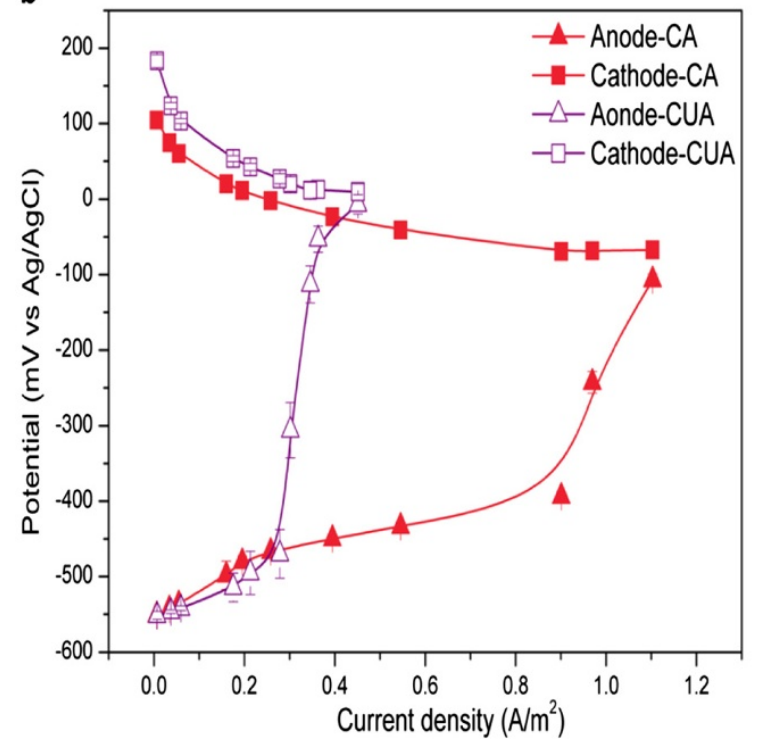

Figure 3 Power density and electrode potentials as a function of current density. (a) Polarization curves, and (b) electrode potentials for conductivity unadjusted (CUA) and adjusted (CA) solutions with hydrolysate of a COD concentration of $400 \mathrm{mg} / \mathrm{L}$. The conductivity was adjusted from $5.6 \mathrm{mS} / \mathrm{cm}$ to $17 \mathrm{mS} / \mathrm{cm}$ with addition of $\mathrm{NaCl}$.

can meet the annual demand of 35.56 million people for electric power.

Some factors, including reactor design, distance between electrodes, solution conductivity, and electrode material, can affect the performance of MFCs. In the present study, a graphite brush anode with a large specific surface area for attachment of exoelectrogens was adopted, which was previously reported as very beneficial for power output [21]; whereas on the other hand, it 
is difficult to control the distance between electrodes with the cylindrical type of brush anode, because electrode distance has been verified as an important factor capable of affecting the $R_{\text {int }}$ of MFCs [22]. The $R_{\text {int }}$ of MFCs can be separated into that of the anode, electrolyte, and cathode. The conductivity of the electrolyte can affect the ion transport within the electrolyte. Conductivity adjustment increased the mass transfer rate of organic matters to the anodic biofilm, providing sufficient electron donors and thus, improved the performance of the anodic exoelectrogens. On the other hand, the addition of $\mathrm{NaCl}$ to the electrolyte reduced the performance of the cathode. It has been reported that $\mathrm{Cl}^{-}$can cause deterioration in the performance of $\mathrm{Pt}$ towards the oxygen reduction reaction due to the strong interaction between adsorbed $\mathrm{Cl}^{-}$ and Pt, which could suppress the adsorption of $\mathrm{O}_{2}$ and the formation of Pt site-pairs acquired for breaking the $\mathrm{O}-\mathrm{O}$ band [23]. Moreover, increasing the solution conductivity could promote the ionic transfer rate and thus decrease the solution resistance [24]. Therefore, the overall effects of $\mathrm{NaCl}$ on the anode and electrolyte exceeded that of the cathode, reducing the overall $R_{\text {int }}$ of the MFC and consequently promoting the $\mathrm{P}_{\max }$ output.

\section{Microbial richness and diversity}

Four 16S rRNA gene libraries were constructed for the 454-pyrosequencing. The qualified sequences for the microbial samples were 8,615 to 14,308 (Figure 4). The sequences were clustered to represent operational taxonomic

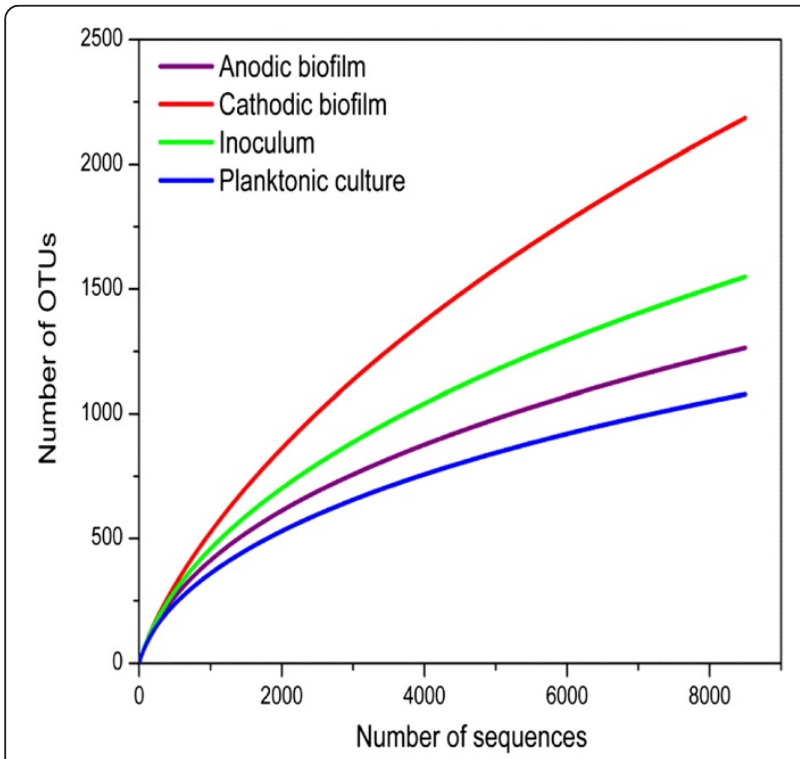

Figure 4 Rarefaction curves based on pyrosequencing of bacterial communities. Samples were collected from anodic and cathodic samples, and planktonic culture. Inoculum was also analyzed to observe the change in microbial structure after

microbial fuel cell operation. The operational taxonomic units (OTUs) were defined at 0.03 distances. units (OTUs) with $3 \%$ nucleotide dissimilarity. To reduce sequencing efforts to compare the number of OTUs exactly, 8,500 sequences were randomly selected to calculate the number of OTUs in each sample. The total observed OTUs were 1,242, 2,200, 1,549 and 1,085 for anodic and cathodic biofilm, inoculums, and planktonic culture, respectively (Additional file 1: Table S1). The results illustrated that MFC operation increased the microbial richness of the cathodic biofilm, whereas the richness of the anodic biofilm and planktonic culture were reduced. The Shannon index provides information on species richness and diversity [25]. The cathodic biofilm showed the largest Shannon index (6.5), followed by the inoculum (6.2), anodic biofilm (5.9), and the planktonic culture (5.7). The Shannon index further confirmed that the operation reduced the microbial diversity of the anodic biofilm, which might be due to the selection of exoelectrogens caused by the generation of electricity [26]. However, the microbial diversity of the cathodic biofilm was increased compared to the inoculum. In an air-cathode MFC, ambient air transfers through the diffusion layer into the anolyte; however, the formation of cathodic biofilm decreases the transfer rate of air into the anolyte, preventing mass transfer of organic matter, and the transport of $\mathrm{OH}^{-}$out of the biofilm [27]. Therefore, the formation of cathodic biofilm resulted in respiratory environments with different levels of oxygen, organic matter concentration, and $\mathrm{pH}$. This could be the reason why there was an increase in microbial diversity in the cathodic biofilm. In an air-diffusion biocathode MFC, however, the microbial diversity in cathodic biofilm was smaller than that in planktonic culture [28], possibly due to the different MFC configuration and carbon source.

\section{Microbial community analysis}

A taxonomic supervised dendrogram was prepared to examine the overall variation in the microbial community of the samples. As demonstrated in Figure 5a, the anodic biofilm and planktonic culture were relatively well-clustered, and the cathodic biofilm was clustered closer to the inoculum in comparison to the anodic and planktonic culture. The results indicated that the electrode reactions and niches could influence the microbial community structure which was significantly differentiated from that of the inoculum.

Figure $5 \mathrm{~b}$ shows the relative abundance of the four microbial communities at phylum level. Proteobacteria including $\alpha-, \beta-, \delta$ - and $\gamma$ - was the predominant phylum accounting for $44.2 \%, 41.9 \%, 55.2 \%$ and $29.8 \%$ of the total abundance in the anodic and cathodic biofilm, planktonic culture and inoculum, respectively. Among the Proteobacteria, the $\delta$ - class showed a great increase from $5.0 \%$ in the inoculum to $11.1 \%$ to $25.0 \%$ in the MFC samples; the $\alpha$ - class increased from $7.5 \%$ in the inoculum to $8.8 \%$ in the planktonic culture, and $17.9 \%$ in the cathodic biofilm, 


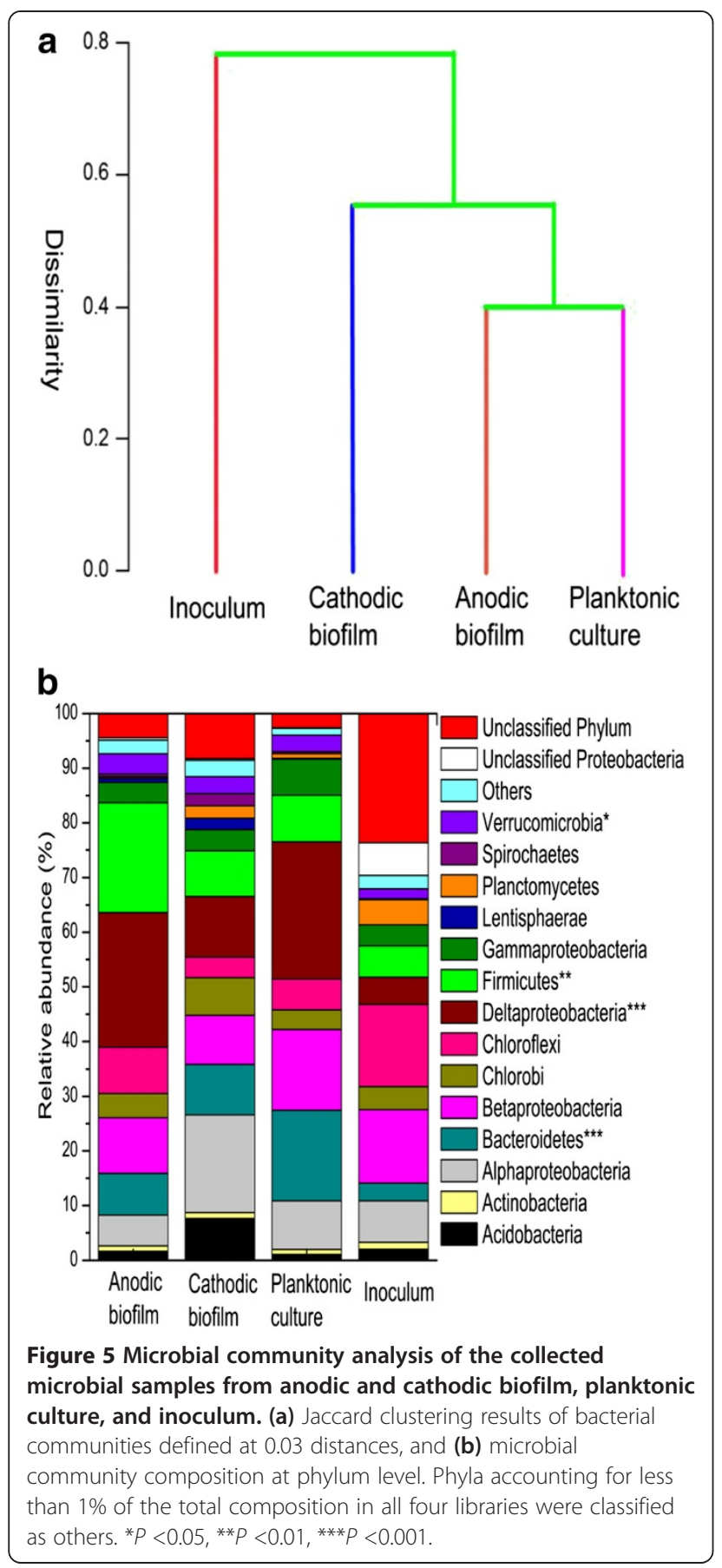

whereas it decreased to $5.6 \%$ in the anodic biofilm. Moreover, Bacteroidetes increased from $3.3 \%$ in the inoculum to $7.7 \%$ in the anodic biofilm, $9.2 \%$ in the cathodic biofilm, and $16.6 \%$ in the planktonic culture; Firmicutes were enriched from $5.8 \%$ in the inoculum to $20.1 \%$, $8.3 \%$, and $8.6 \%$ in the anodic biofilm, cathodic biofilm and planktonic culture, respectively. Bacteroidetes and Firmicutes made up the subdominant members accounting for $27.7 \%$ in the anodic biofilm, $17.5 \%$ in the cathodic biofilm, and
$25.2 \%$ in the planktonic culture, respectively. Chloroflexi was reduced after MFC operation from $15.0 \%$ in the inoculum to $8.4 \%, 3.8 \%$, and $5.7 \%$ in the anodic biofilm, cathodic biofilm, and the planktonic culture, respectively. Furthermore, unclassified phylum was significantly reduced to $2.6 \%$ to $8.3 \%$ in the MFC samples from $23.7 \%$ in the inoculum. As previously reported, the species, such as Shewanella putrefacies IR-1 [29], Geobacter sulfurreducens [30], and Ochrobacrum anthropi YZ-1 [31] belonging to Proteobacteria were the most important exoelectrogens in the anodic biofilm. Moreover, a few isolated exoelectrogens belonging to Firmicutes such as Clostridium butyricum EG3 [32], Desulfitobacterium hafniense strain DCB2 [33], Thermincola sp. strain JR [34], and Thermincola ferriacetica [35], were known as a source of exoelectrogens. The present results differed from that of the observed exoelectrogens of a two-chambered MFC using wheat straw biomass for which the predominant culture was Bacteroidetes with $40 \%$ of sequences [16]. And Bacteroidetes and $\gamma$-proteobacteria were the most abundant phylum in the anodic biofilm of an air-cathode dualchamber MFC fed with glucose and glutamate [36]. In MFCs, the microbial community was greatly influenced by the substrates, operation time, and architecture of the cell $[16,37,38]$. Rice straw hydrolyte generally consists of glucose, xylose, arabinose, acetic acid, and small amount of furfural and 5-hydroxymethyl-furfural [39]. The component of rice straw hydrolyte and singlechamber design in the present study is proposed the factor resulting in different microbial community to the previous studies.

Proteobacteria $(41.9 \%, \alpha-17.9 \%, \delta-11.1 \%, \beta-9.0 \%$, and $\gamma-$ $3.8 \%)$, Bacteroidetes (9.2\%), Firmicutes (8.3\%), Acidobacteria (7.6\%), and Chlorobi (6.9\%) made up the dominant groups of the cathodic biofilm in this study. In a twochamber air-diffusion biocathode MFC, the dominant groups were observed as Proteobacteria (39.9\%, $\alpha-31.7 \%$, $\gamma-3.8 \%, \beta-2.5 \%$, and $\delta$ - $1.1 \%)$, Planctomycetes $(29.9 \%)$ and Bacteroidetes (13.3\%) [28]. The cathodic biofilm in an air-cathode single-chamber MFC can utilize organic carbon sources whereas the cathodic biofilm in a twochamber air-diffusion MFC was fed with an inorganic carbon source, such as $\mathrm{NaHCO}_{3}$. This should be the reason for the different dominant groups in the two cathodic biofilms.

A total of 484 genera were obtained using the Ribosomal Database Project (RDP) classifier, of which 114 genera were commonly shared by all samples (Figure 6a). They accounted for $85.9 \%, 79.8 \%, 82.1 \%$ and $79.5 \%$ of the anodic and cathodic biofilm, planktonic culture and inoculum, respectively (Figure 6b). There were 182 genera that appeared in only one sample, accounting for $0.4 \%, 3.1 \%, 0.1 \%$ and $5.3 \%$ of the classified sequences in the anodic and cathodic biofilm, planktonic culture and 


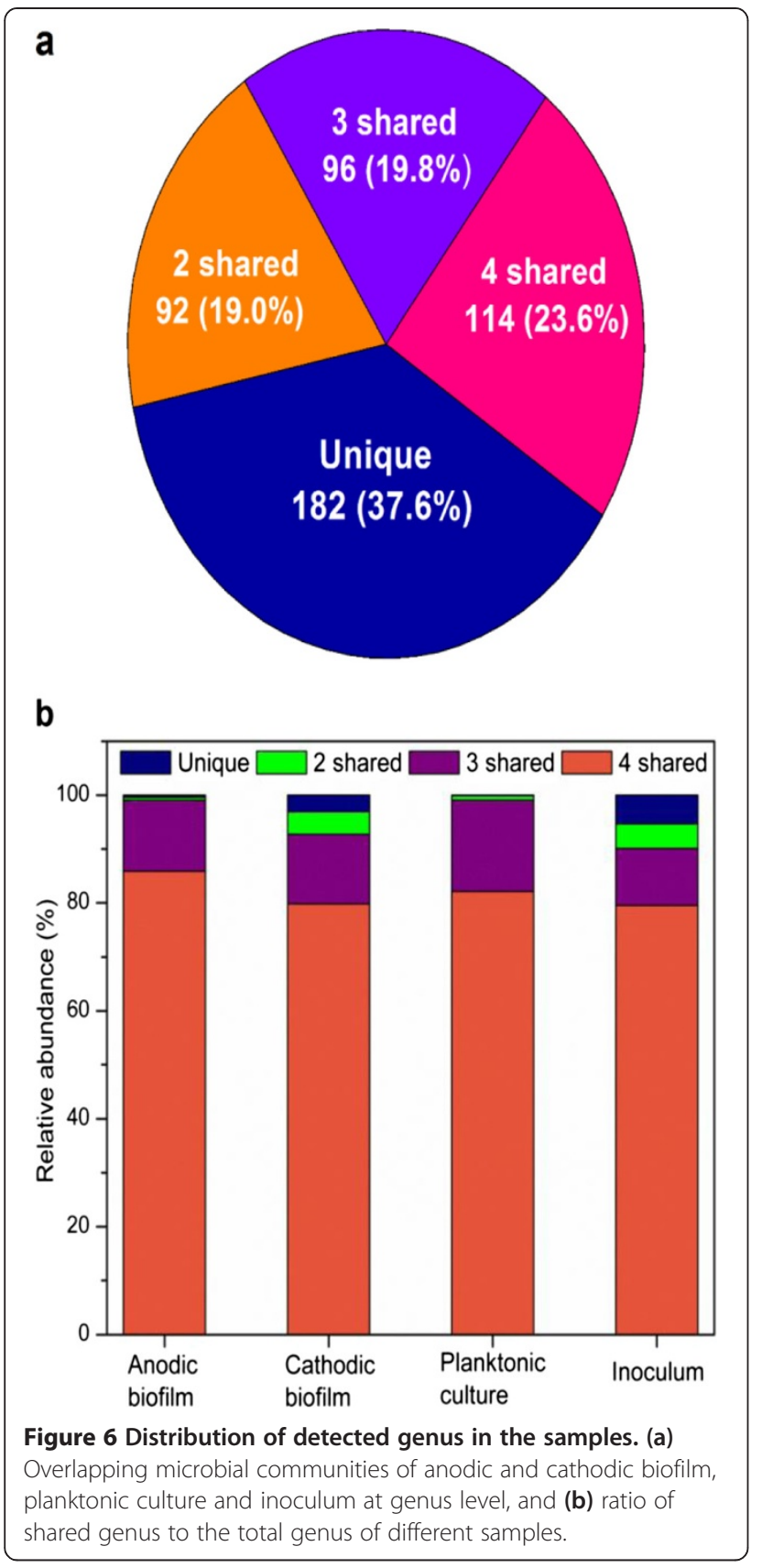

inoculum, respectively. The results suggested that the differentiation of microbial community structure in the samples was caused by a minor portion of the genus.

\section{Exoelectrogens}

Exoelectrogens play a key role in the generation of electric power through transferring electrons produced from organic matters to the surface of anode materials. Exoelectrogens observed in the present study with greater than $1 \%$ abundance are summarized in Table 1 . In anodic biofilm, five genera of known exoelectrogens accounted for $23.5 \%$ in total communities, including Desulfobulbus
Table 1 Exoelectrogenic genus observed in different MFC samples and the inoculum ( $>1 \%)$

\begin{tabular}{lllll}
\hline Genus & $\begin{array}{l}\text { Anodic } \\
\text { biofilm, \% }\end{array}$ & $\begin{array}{l}\text { Planktonic } \\
\text { culture, \% }\end{array}$ & $\begin{array}{l}\text { Cathodic } \\
\text { biofilm, \% }\end{array}$ & Inoculum, \% \\
\hline Clostridium & - & - & - & 1.6 \\
Comamonas & 1.4 & 2.2 & 1.9 & - \\
Desulfobulbus & 11.0 & 19.0 & 7.8 & - \\
Desulfovibrio & 3.6 & 4.5 & 1.3 & - \\
Geobacter & 5.3 & - & - & - \\
Pseudomonas & 2.3 & 2.9 & - & - \\
\hline
\end{tabular}

(11.0\%), Geobacter (5.3\%), Desulfovibrio (3.6\%), Pseudononas (2.3\%), and Comamonas (1.4\%). The genera of exoelectrogens in planktonic culture included Desulfoblbus (19.0\%), Desulfovibrio (4.5\%), Pseudomonas (2.9\%), and Comamonas (2.2\%), accounting for $28.5 \%$ of the total genus. For the cathodic biofilm, however, exoelectrogen species was reduced to three genera, including Desulfoblbus (7.8\%), Comamonas (1.9\%), and Desulfovibrio (1.3\%), with a total abundance of $11.0 \%$. In the inoculum, only one genus with an abundance greater than 1\% (Clostridium, $1.6 \%)$ was discovered, demonstrating that the electricity production can influence the richness of exoelectrogens in MFCs. On the other hand, Clostridium was significantly reduced after MFC operation, indicating that the genus of Clostridium lost the competition of electron generation compared to other exoelectrogens. The genus of Desulfobulbus was the common predominant exoelectrogen in anodic and cathodic biofilm, and planktonic culture, demonstrating that this genus was well adopted in the operating conditions and might attribute to the power generation as a main exoelectrogen in the electrodes. Pseudomonas was shared in the anodic biofilm and planktonic culture, but not in the cathodic biofilm, indicating that Pseudomonas was not suitable to utilize external electron transferred from the anode. Geobacter, an important genus attributing to the power generation in an MFC [40,41], was only dominant in the anodic biofilm. Among the Geobacter species, G. sulfurreducens and G. metallireducens, which were revealed to transfer electrons through nanowire to electron acceptors [42], accounted for $2.9 \%$ and $0.2 \%$ of the total abundance, respectively. These results suggested the attribution of Geobacter species to current generation in the present study. In MFCs, an opposite electron flow of the anode and cathode reaction occurred, and the physical and chemical environment in the anodic and cathodic biofilm was also different. This might be the reason for the different predominant exoelectrogens observed in the anodic and cathodic biofilm.

\section{Sulfate reducing bacteria}

The diluted-acid treatment of rice straw produced sulfate as a main component of the rice straw hydrolysate. 
The sulfate-reducing bacteria (SRB) could serve a main role in sulfate reduction in this study. Twenty genera of putative sulfate and sulfur-reducing bacteria were detected, and belonged to $\delta$-proteobacteria and Firmicutes. The dominant members were Desulfobulbus, Desulfovibrio, Desulfomicobium, Desulforhabdus and Geobacter (Additional file 1: Table S2), of which Desulfobulbus, Desulfovibrio and Geobacter are well-known to play an important role in transferring electrons to the anode. The abundance of SRB was remarkably increased in the three MFC samples compared with the inoculum community. The SRB from the anodic biofilm and planktonic culture were approximately three times more abundant than in the cathodic biofilm. A relatively low abundance of SRB in the cathodic biofilm can be explained by the diffused oxygen to the cathodic biofilm which might have competed with sulfate as an electron acceptor. Interestingly, a considerably higher number of SRB such as Desulfobulbus and Desulfovibrio were observed in the planktonic culture than in the anodic biofilm. The results showed opposite trends in other dominant groups such as Desulfomicobium, Desulforhabdus, and Geobacter, representing greater abundance in the anodic biofilm than in the planktonic culture. Although SRB was reported to play an important role in transferring electrons on the anode, some groups of SRB that could not form biofilm on the electrode may also reduce sulfate in the planktonic niche [42]. It has already been reported that SRB demonstrate functional dynamics, including electron transfer, sulfate reduction, and converting organic matters, such as acetic and butyric acids to alcohols and acetone via direct electron transfer [43-45]. In the present study, therefore, high-abundance groups (Desulfobulbus and Desulfovibrio) may perform both electron transfer on the electrode and sulfate reduction in the electrolyte, whereas low-abundance groups may focus primarily on transferring electrons in the electrode.

\section{Conclusions}

The present study confirmed that rice straw hydrolysate is flexible as fuel for MFCs to generate electric power. The microbial community was differentiated after the MFC operation. Furthermore, the differentiation in the microbial community structure resulted from a small portion of the genus. The microbial community of the anodic biofilm had a similar microbial structure to the planktonic culture, but it was different to the cathodic biofilm. The known exoelectrogens were differently enriched depending on the niches caused by the different electrode reaction and respiratory environment. Sulfate-reducing bacteria were greatly abundant due to sulfate production by the dilute-acid treatment of the rice straw. They might play different roles in different niches.

\section{Materials and methods}

\section{Rice straw hydrolysate preparation}

The rice straw collected from Daejeon, Korea was rinsed with tap water and then distilled water, and further dried in an oven at $50^{\circ} \mathrm{C}$. The dried rice straw was milled with a juice extractor and was then hydrolyzed using the dilutedacid method (1:10, w/v) [46]. The hydrolysate was further treated by an over-liming process as previously reported to reduce toxic inhibitors [47]. The $\mathrm{pH}$ of the resultant hydrolysate was adjusted to approximately 7.0 with concentrated $\mathrm{H}_{2} \mathrm{SO}_{4}$, and the residue was separated by centrifugation (3,000 rpm, 3 minutes). The COD concentration of the resultant hydrolysate was $20,689 \mathrm{mg} / \mathrm{L}$.

\section{MFC fabrication}

The MFC reactor was made of Plexi-glass $(6 \mathrm{~cm} \times 6 \mathrm{~cm} \times$ $6.5 \mathrm{~cm}$ ), with $220 \mathrm{~mL}$ of working volume. The carbon brush anode (length $2 \mathrm{~cm}$, diameter $3 \mathrm{~cm}$ ) was prepared by twisting carbon fiber (PANEX ${ }^{\odot} 35$, Zoltek) with stainless steel wire. The cathode was a commercially available ELAT $^{\circledast}$ gas diffusion electrode (Lot \#LT 120E-W: 090205) with Pt catalyst (20\%). The catalyst side of the cathode was coated with Nafion ${ }^{\bullet}$ polymer dispersion (5\%, Aldrich) and dried in air, leading to a Nafion loading rate of $0.5 \mathrm{mg} / \mathrm{cm}^{2}$. The effective area of the cathode was $36 \mathrm{~cm}^{2}$. To determine the anodic potential, an $\mathrm{Ag} / \mathrm{AgCl}$ (3.3 M $\mathrm{KCl})$ was introduced to the electrolyte.

\section{Culture inoculation and MFC operation}

To start up the MFC, $10 \mathrm{~mL}$ anaerobic sludge collected from the anaerobic digester of a wastewater treatment plant in Orgchen, Korea was mixed with $210 \mathrm{~mL}$ medium solution and pumped into the MFC. The medium solution contained $0.1 \mathrm{~g} / \mathrm{L} \mathrm{KCl}, 0.5 \mathrm{~g} / \mathrm{L} \mathrm{NH} \mathrm{NH}_{4}, 0.1 \mathrm{~g} / \mathrm{L} \mathrm{MgCl}_{2}$, $0.1 \mathrm{~g} / \mathrm{L} \mathrm{CaCl} \mathrm{Ca}_{2}, 0.3 \mathrm{~g} / \mathrm{L} \mathrm{KH}_{2} \mathrm{PO}_{4}, 0.5 \mathrm{~g} / \mathrm{L} \mathrm{NaHCO}$, and $1.36 \mathrm{~g} / \mathrm{L} \mathrm{CH} \mathrm{CH}_{3} \mathrm{COONa} \cdot 3 \mathrm{H}_{2} \mathrm{O}$ as an electron donor. Each time the voltage at a fixed external resistance of $500 \Omega$ dropped below $35 \mathrm{mV}$, sodium acetate was added to the solution until there was a repeatable voltage output. After the cell was successfully started up, the solution was switched to rice straw hydrolysate which was diluted to different COD concentrations (100, 150, 200, and $400 \mathrm{mg} / \mathrm{L}$ ) with distilled water and then buffered with $1.05 \mathrm{~g} / \mathrm{L} \mathrm{NH} \mathrm{NH}_{4} \mathrm{Cl}, 1.5 \mathrm{~g} / \mathrm{L} \mathrm{KH}_{2} \mathrm{PO}_{4}$, and $2.2 \mathrm{~g} / \mathrm{L}$ $\mathrm{K}_{2} \mathrm{HPO}_{4}$. All the experiments were performed by batch mode and the solution was stirred with a magnetic stirring bar. Temperature was controlled at $30 \pm 1^{\circ} \mathrm{C}$ in an incubator.

\section{Analysis and calculation}

COD was analyzed following the standard method of Korea after filtering through a glass filter paper to remove bacteria. Voltage (V) was monitored using a LabView 
program every ten minutes. Power density was normalized to the cathode surface area $(\mathrm{A})$ as follows:

$$
P=V^{2} / R \cdot A,
$$

and current density $(\mathrm{j})$ was calculated as follows:

$$
j=V / R \cdot A,
$$

where $\mathrm{R}$ is the external resistance. In order to determine the $P_{\max }$, the external resistance was varied between $30 \mathrm{k}$ and $10 \Omega$. To observe the effect of conductivity on the performance of the MFC, the conductivity of the electrolyte was adjusted from $5.6 \mathrm{mS} / \mathrm{cm}$ to $17 \mathrm{mS} / \mathrm{cm}$ using $\mathrm{NaCl}$. The CE was calculated as:

$$
C E=C_{i} / C_{o},
$$

where $\mathrm{C}_{\mathrm{i}}$ is the coulomb collected from the passed current and $C_{o}$ is the coulomb generated from the consumed organic matters. $R_{\text {int }}$ was determined as the slope of the $\mathrm{i}-\mathrm{V}$ curve according to:

$$
V=U_{\text {cell }}-i R_{\text {int }},
$$

where $U_{\text {cell }}$ is the electromotive force of the cell [15].

\section{Microbial analysis \\ DNA extraction, $P C R$, and FLX titanium pyrosequencing}

Samples were collected from inoculum sludge, anodic and cathodic biofilm, and planktonic culture for microbial analysis. DNA was extracted using PowerSoil ${ }^{\text {Th }}$ DNA Isolation Kit (MoBio, Carlsbad, CA, USA) following the manufacturer's instructions. The following universal $16 \mathrm{~S}$ rRNA primers were used for the PCR reactions: F563 (AYTGGGYDTAAAGNG) and BSR926 (CCGTCAATT YYTTTRAGTTT). Barcode sequences (AGCATCTG, A GCATGAG, AGCTCAGC and AGCTCATG for anodic biofilm, cathodic biofilm, planktonic culture, and inoculum, respectively) were attached between the 454 adaptor sequence and the forward primers. Each PCR reaction was carried out with two of the $25-\mu \mathrm{l}$ reaction mixtures containing 60 ng of DNA, $10 \mu \mathrm{M}$ of each primer (Macrogen, Seoul, Korea), and AccuPrime ${ }^{\mathrm{ma}}$ Taq DNA Polymerase High Fidelity (Invitrogen, Madison, WI, USA) in order to obtain the following final concentrations: $1.25 \mathrm{U}$ of Taq polymerase, $50 \mathrm{mM}$ of $\mathrm{MgSO}_{4}$, and 10× of the PCR buffer. A C1000TM thermal cycler (Bio-rad, Hercules, CA, USA) was used for the PCR as follows: (i) an initial denaturation step at $94^{\circ} \mathrm{C}$ for 3 minutes, (ii) 30 cycles of annealing and extending (each cycle occurred at $95^{\circ} \mathrm{C}$ for $60 \mathrm{~s}$ followed by $55^{\circ} \mathrm{C}$ for $45 \mathrm{~s}$ and an extension step at $72^{\circ} \mathrm{C}$ for $60 \mathrm{~s}$ ), and (iii) the final extension at $72^{\circ} \mathrm{C}$ for 5 minutes. After this PCR amplification, the amplicons were purified by one-time gel electrophoresis/isolation and two-time purifications using a QIAquick Gel extraction kit (Qiagen, Valencia, CA, USA) and QIAquick PCR purification kit
(Qiagen). In order to recover a sufficient amount of purified amplicons from the purification steps, two $25-\mu \mathrm{l}$ reaction mixtures were combined into one prior to amplicon purification. All four amplicons were pooled and amplicon pyrosequencing was performed by Macrogen Inc. (Seoul, South Korea) using a 454/Roche GS-FLX titanium instrument (Roche, Nutley, NJ, USA).

\section{Microbial community and classification}

Sequences were analyzed following the modified protocol using Mothur. The range of flow was modified from 450 to 720 to obtain highly accurate sequences. Chimera sequences were removed by the Uchime algorithm with self-references. Filtered sequences were aligned to Silva Gold aligned sequences, and clustered with the furthest algorithm at 0.03 distances. Sequences were classified using the RDP training set (Version 9) with a threshold of $50 \%$. Classified sequences were analyzed into phylotype at phylum and genus level. To reduce sequencing efforts from samples, the smallest sequence numbers were selected to measure the alpha diversity, such as observed OTUs, the Shannon index, and rarefaction curves. A taxonomy-supervised dendrogram was constructed to compare microbial communities from samples using relative abundances. After calculating the relative abundance of genus including unclassified sequences at genus level, a distance matrix (vegdist) was produced and clustered through the average algorithm (hclust) using Vegan package from $\mathrm{R}$.

\section{Additional file}

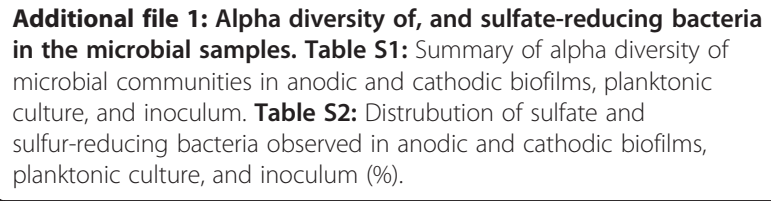

\section{Abbreviations}

CE: Coulombic efficiency; COD: Chemical oxygen demand; MFC: Microbial fuel cell; OTU: Operational taxonomic unit; $P_{\max }$ : maximum power density; RDP: Ribosomal Database Project; $R_{\text {int }}$ internal resistance; SRB: Sulfatereducing bacteria.

\section{Competing interests}

The authors declare that they have no competing interests.

\section{Authors' contributions}

ZW designed the research and performed the MFC operation. TL carried out the microbial community analysis and prepared the related part of manuscript. ZW prepared the manuscript. BL, CC and JP reviewed the manuscript. All authors read and approved the final manuscript.

\section{Acknowledgement}

This work was supported by the National Research Foundation of Korea (NRF) grant funded by the Korea government (MEST) (No.

2012R1A1A2009500). Thanks should be given to Ms Jane Eumie Choi and Dr Euree Choi for help with English editing. 


\section{Author details}

${ }^{1}$ Department of Environmental Engineering, Daejeon University, Daejeon, South Korea. ²Department of Applied Chemistry, Daejeon University, Daejeon, South Korea. ${ }^{3}$ School of Civil and Environmental Engineering, Yonsei University, Seoul, South Korea. ${ }^{4}$ Institute of Urban Environment, Chinese Academy of Sciences, Urban, China. ${ }^{5}$ Department of Microbiology and Ecosystem Science, University of Vienna, Vienna, Austria.

Received: 21 August 2013 Accepted: 8 January 2014

Published: 17 January 2014

\section{References}

1. Zhao F, Rahunen N, Varcoe JR, Chandra A, Avignone-Rossa C, Thumser AE, Slade RCT: Activated carbon cloth as anode for sulfate removal in a microbial fuel cell. Environ Sci Technol 2008, 42:4971-4976.

2. Wang $\mathrm{Z}$, Lim B, Choi C: Removal of $\mathrm{Hg}^{2+}$ as an electron acceptor coupled with power generation using a microbial fuel cell. Bioresour Technol 2011, 102:6304-6307.

3. Pant D, Van Bogaert G, Diels L, Vanbroekhoven K: A review of the substrates used in microbial fuel cells (MFCs) for sustainable energy production. Bioresour Technol 2010, 101:1533-1543.

4. He Y, Pang Y, Liu Y, Li X, Wang K: Physicochemical characterization of rice straw pretreated with sodium hydroxide in the solid state for enhancing biogas production. Energy Fuel 2008, 22:2775-2781.

5. Elmekawy A, Diels L, De Wever H, Pant D: Valorization of cereal based biorefinery byproducts: reality and expectations. Environ Sci Technol 2013, 47:9014-9027.

6. Roberto IC, Mussatto SI, Rodrigues RCLB: Dilute-acid hydrolysis for optimization of xylose recovery from rice straw in a semi-pilot reactor. Industrial Crops and Products 2003, 17:171-176.

7. Pant D, Singh A, Van Bogaert G, Irving Olsen S, Singh Nigam P, Diels L, Vanbroekhoven K: Bioelectrochemical systems (BES) for sustainable energy production and product recovery from organic wastes and industrial wastewaters. RSC Advances 2012, 2:1248.

8. Chae KJ, Choi MJ, Lee JW, Kim KY, Kim IS: Bioresour Technol. Effect of different substrates on the performance, bacterial diversity, and bacterial viability 2009, 100:3518-3525.

9. Ha PT, Tae B, Chang IS: Performance and bacterial consortium of microbial fuel cell fed with formate. Energy Fuel 2008, 22:164-168.

10. Luo Y, Zhang R, Liu G, Li J, Li M, Zhang C: Electricity generation from indole and microbial community analysis in the microbial fuel cell. J Hazard Mater 2010, 176:759-764.

11. Zhang XY, Cheng SA, Wang X, Huang X, Logan BE: Separator characteristics for increasing performance of microbial fuel cells. Environ Sci Technol 2009, 43:8456-8461.

12. Cristiani P, Carvalho ML, Guerrini E, Daghio M, Santoro C, Li B: Cathodic and anodic biofilms in single chamber microbial fuel cells. Bioelectrochem 2013, 92:6-13.

13. Yan H, Saito T, Regan JM: Nitrogen removal in a single-chamber microbial fuel cell with nitrifying biofilm enriched at the air cathode. Water Res 2012, 46:2215-2224.

14. Sevda S, Dominguez-Benetton $\mathrm{X}$, Vanbroekhoven $\mathrm{K}$, De Wever $\mathrm{H}$, Sreekrishnan TR, Pant D: High strength wastewater treatment accompanied by power generation using air cathode microbial fuel cell. Appl Energy 2013, 105:194-206.

15. Wang $Z$, Lim B, Lu H, Fan J, Choi C: Cathodic reduction of $\mathrm{Cu}^{2+}$ and electric power generation using a microbial fuel cell. $B$ Korean Chem Soc 2010, 31:2025-2030

16. Zhang Y, Min B, Huang L, Angelidaki I: Generation of electricity and analysis of microbial communities in wheat straw biomass-powered microbial fuel cells. Appl Environ Microbiol 2009, 75:3389-3395.

17. Zuo $Y$, Maness $P$, Logan BE: Electricity production from steam-exploded corn stover biomass. Energy Fuel 2006, 20:1716-1721.

18. Nam JY, Kim HW, Lim KH, Shin HS: Effects of organic loading rates on the continuous electricity generation from fermented wastewater using a single-chamber microbial fuel cell. Bioresour Techno/ 2010, 101:S33-S37.

19. Lu N, Zhou S, Zhuang L, Zhang J, Ni J: Electricity generation from starch processing wastewater using microbial fuel cell technology. Biochem Eng J 2009, 43:246-251.
20. Liu H, Logan BE: Electricity generation using an air-cathode single chamber microbial fuel cell in the presence and absence of a proton exchange membrane. Environ Sci Technol 2004, 38:4040-4046.

21. Logan B, Cheng S, Valerie W, Estadt G: Graphite fiber brush anodes for increased power production in air-cathode microbial fuel cells. Environ Sci Technol 2007, 41:3341-3346.

22. Liu H, Cheng SA, Logan BE: Power generation in fed-batch microbial fuel cells as a function of ionic strength, temperature, and reactor configuration. Environ Sci Technol 2005, 39:5488-5493.

23. Stamenkovic V, Markovic NM, Ross JPN: Structure-relationships in electrocatalysis oxygenreduction and hydrogen oxidation reactions on $\mathrm{Pt}(111)$ and $\mathrm{Pt}(100)$ in solutions containing chloride ions. J Electroanal Chem 2001, 500:44-51.

24. Elmekawy A, Hegab HM, Dominguez-Benetton X, Pant D: Internal resistance of microfluidic microbial fuel cell: challenges and potential opportunities. Bioresour Technol 2013, 142:672-682.

25. Shannon CE, Weaver W: The Mathematical Theory of Communication. Urbana: University of Illinois Press; 1949.

26. Jong BC, Kim BH, Chang IS, Liew PWY, Choo YF, Kang GS: Enrichment, performance, and microbial diversity of a thermophilic mediatorless microbial fuel cell. Environ Sci Technol 2006, 40:6449-6454.

27. Yuan $Y$, Zhou S, Tang J: In situ investigation of cathode and local biofilm microenvironments reveals important roles of $\mathrm{OH}^{-}$and oxygen transport in microbial fuel cells. Environ Sci Technol 2013, 47:4911-4917.

28. Wang Z, Zheng Y, Xiao Y, Wu S, Wu Y, Yang Z, Zhao F: Analysis of oxygen reduction and microbial community of air-diffusion biocathode in microbial fuel cells. Bioresour Technol 2013, 144:74-79.

29. Kim B, Kim H, Hyun M, Park D: Direct electrode reaction of Fe(III)-reducing bacterium, Shewanella putrefaciens. J Microbiol Biotechnol 1999, 9:127-131.

30. Bond DR, Holmes DE, Tender LM, Lovley DR: Electrode-reducing microorganisms that harvest energy from marine sediments. Science 2002, 295:483-485.

31. Zuo Y, Xing D, Regan JM, Logan BE: Isolation of the exoelectrogenic bacterium ochrobactrum anthropi $\mathrm{YZ}-1$ by using a U-tube microbial fuel cell. Appl Environ Microbiol 2008, 74:3130-3137.

32. Park HS, Kim BH, Kim HS, Kim HJ, Kim GT, Kim M, Chang IS, Park YK, Chang $\mathrm{HI}$ : A novel electrochemically active and Fe(III)-reducing bacterium phylogenetically related to Clostridium butyricum isolated from a microbial fuel cell. Anaerobe 2001, 7:297-306.

33. Milliken CE, May HD: Sustained generation of electricity by the sporeforming, Gram-positive, Desulfitobacterium hafniense strain DCB2. Appl Microbiol Biotechnol 2006, 73:1180-1189.

34. Wrighton KC, Agbo P, Warnecke F, Weber KA, Brodie EL, DeSantis TZ, Hugenholtz P, Andersen GL, Coates JD: A novel ecological role of the Firmicutes identified in thermophilic microbial fuel cells. Isme J 2008, 2:1146-1156.

35. Marshall CW, May HD: Electrochemical evidence of direct electrode reduction by a thermophilic Gram-positive bacterium. Thermincola ferriacetica. Energy Environ Sci 2009, 2:699-705.

36. Kim GT, Webster G, Wimpenny JWT, Kim BH, Kim HJ, Weightman AJ: Bacterial community structure, compartmentalization and activity in a microbial fuel cell. J Appl Microbio/ 2006, 101:698-710.

37. Zhang Y, Min B, Huang L, Angelidaki I: Electricity generation and microbial community response to substrate changes. Bioresour Technol 2011, 102:1166-1173.

38. Beecroft NJ, Zhao F, Varcoe JR, Slade RCT, Thumser AE, Avignone-Rossa C: Dynamic changes in the microbial community composition in microbial fuel cells fed with sucrose. Appl Microbiol Biotechnol 2011, 93:423-437.

39. Huang C, Zong M, Wu H, Liu Q: Microbial oil production from rice straw hydrolysate by Trichosporon fermentans. Bioresour Technol 2009, 100:4535-4538.

40. Bond DR, Lovley DR: Electricity production by Geobacter sulfurreducens attached to electrodes. Appl Environ Microbiol 2003, 69:1548-1555.

41. Nercessian O, Parot S, Délia M, Bergel A, Achouak W: Harvesting electricity with Geobacter bremensis isolated from compost. PLOS ONE 2012, 7:e34216.

42. Malvankar NS, Lovley DR: Microbial nanowires: a new paradigm for biological electron transfer and bioelectronics. ChemSusChem 2012, 5:1039-1046.

43. Santegoeds CM, Ferdelman TG, Muyzer G, Beer DD: Structural and functional dynamics of sulfate-reducing populations in bacterial biofilms. Appl Environ Microbiol 1998, 64:3731-3739. 
44. Cordas C, Guerra L, Xavier C, Moura J: Electroactive biofilms of sulphate reducing bacteria. Electrochim Acta 2008, 54:29-34.

45. Sharma M, Aryal N, Sarma PM, Vanbroekhoven K, Lal B, Benetton XD, Pant $D$ : Bioelectrocatalyzed reduction of acetic and butyric acids via direct electron transfer using a mixed culture of sulfate-reducers drives electrosynthesis of alcohols and acetone. Chem Commun 2013, 49:6495-6497.

46. Yoswathana N, Phuriphipat P, Treyawutthiwat P, Eshtiaghi MN: Bioethanol production from rice straw. Energy Res $J$ 2010, 1:26-31.

47. Martinez A, Rodriguez ME, York SW, PRESTON JF, Ingram LO: Effects of Ca $(\mathrm{OH})_{2}$ treatments ("overliming") on the composition and toxicity of bagasse hemicellulose hydrolysates. Biotechnol Bioeng 2000, 69:526-536.

doi:10.1186/1754-6834-7-9

Cite this article as: Wang et al:: Microbial community structures differentiated in a single-chamber air-cathode microbial fuel cell fueled with rice straw hydrolysate. Biotechnology for Biofuels 2014 7:9.

\section{Submit your next manuscript to BioMed Central and take full advantage of:}

- Convenient online submission

- Thorough peer review

- No space constraints or color figure charges

- Immediate publication on acceptance

- Inclusion in PubMed, CAS, Scopus and Google Scholar

- Research which is freely available for redistribution 